\title{
Introduction: \\ The Reflexive Appropriation of Space
}

\author{
Daniel Boscaljon
}

\section{I: The possibilities of SPACE in Dickinson's "Four Trees"}

We must be careful when speaking about SPACE as it often leads to empty thoughts. Although we are surrounded by spaces and cannot experience our environments without presupposing space, its omnipresence (both physical and conceptual) makes it difficult to grasp. This difficulty is compounded by the fact that definitions of space frequently rely on cognate concepts-time and place-that confuse rather than clarify what the term "space" might mean. Space is vast and requires that we experience it through boundaries. We learn space through mediated encounters.

More significantly, spaces intentionally altered for cultural reasons, whether to promote specific forms of community or to engender a particular individual experience, introduce more variables to consider before articulating what that space can mean-both for itself, and for an expanded awareness of the value of thinking critically about spaces. Space, in other words, is not neutral: the spaces that we inhabit or frequent tend to influence our actions and values. Our preunderstandings of certain spaces-remaining reverent within a space considered "sacred" by a community, accepting joyful frolics in spaces set aside for frivolity and laughter, respecting silence in spaces of thought—allow us to navigate our worlds with diminished impatience and frustration. We understand, more or less, what we can expect from the spaces where we place ourselves and spending time within these spaces attunes us to their nuances: we learn more of what to expect and how we should behave as we spend more time within them. 
Emily Dickinson's Fr778, a poem that Christopher Benfey describes as "one of Dickinson's fullest and happiest expressions of the relation between nature and the human knower" (113), provides an example of a textual space that plays upon ways that our perception simultaneously reveals and conceals (in time) the multiple potentialities for a true experience of a given environmental expanse. She writes:

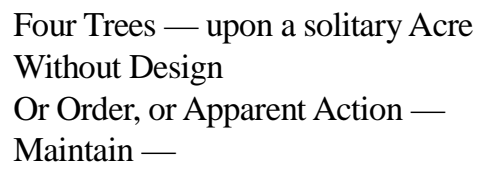

The Sun — upon a Morning meets them The Wind -

No nearer Neighbor — have they — But God -

The Acre gives them — Place-

They — Him — Attention of Passer by Of Shadow, or of Squirrel, haply -

Or Boy -

What Deed is Their's unto the General Nature-

What Plan

They severally — retard — or further —

Unknown -

The various interpretations of Dickinson's meditation focus primarily on her language (Miller, Benfey) and the ecological implications of place (Christine Gerhardt's reading is particularly impressive). My interest in offering the poem is to show how its space juxtaposes the cultural and the natural senses of space in a particularly apt way.

The space that Dickinson evokes is an "Acre," a term that itself suggests a variety of perspectives on the same space. According to the 1831 Webster's dictionary that Dickinson was fond of consulting, the term acre has many cognates in other languages: in English, the "primitive sense" of the term as "an open, plowed, or sowed field" had been "limited to a definite quantity" by various legal statues, such that the English statute acre was "A quantity of land, containing 160 square rods or perches, or 4840 square yards.” Dickinson's use of Acre here enfolds two disjunctive possibilities: it is a measured and calculated plot of land as well as one whose disorder invites a more "primitive" apprehension of the space. What Dickinson contributes to the initial "natural" space (assuming an originary field) is this precise tension: using the word "Acre" merges two distinct ways of viewing or experiencing space. The space of the poem (and its spaces, including dashes), a space distinct from the natural world, is constructed within this point of tension. The second stanza offers only indirect commentary on the space of the Acre, suggested 
still as the solitary backdrop that allows for an awareness of the trees as a group, discussed here only as "them" and "they"- this choice allows Dickinson to introduce temporality, a "Morning" in time contrasted with the eternal view of the "nearer Neighbor," God. In the third stanza, Dickinson outlines the internal dynamics of the space, showing, as Gerhardt discusses, the interdependence of a number of variables occurring within a space. Thus, "The Acre gives them—Place— / They — Him — Attention of Passer by — / Of Shadow, or of Squirrel, haply — / Or Boy - ": importantly, Dickinson emphasizes that the more personalized "Place" is something given by the Acre, and is not co-extensive with it.

In the final stanza, Dickinson uses the term "Deed" to push readers to clarify the tension initially manifest in the "Acre" of stanza one. Here, the "Deed" simultaneously offers readers connotations of both law and activity: her "What Deed is Their's unto the General Nature- / What Plan" asks the reader to leave the space of uncertainty in order to answer the question of "Deed." If the Acre is a space mediated by measurement and calculation, the question of "Deed" is simply a legal document titling property; on the other hand, if "Deed" refers to the activity of "Maintain" Dickinson introduces in the first stanza, then "Deed" becomes the work of trees. Evidence supporting the sense of the space as abstracted or calculated is offered in line 14, "What Plan," as it presupposes the need for a rational, transcendent moment of organization. Answering the question of "deed" in terms of the activity of maintenance, however, points back to the four trees, which maintain "severally" as they "retard — or further— / Unknown —." The nature of the truth that the trees maintain and invite onlookers to experience is mingled with the unknown and the unknowable. The poem frames an experience of space that attends to that space's potentiality by showing how this space enables experiences of reductive calculation (material and economic understandings of space) as well as expansive appreciation (including religious and poetic understandings of space). The poet preserves the space of tension, offering multiple potentialities while obscuring the definitive truth of the space. Additionally, Dickinson's regard for space manifests within the literary confines of the poem itself: the four stanzas with four lines maintain their own truth without apparent action, anchoring an experience that parallels that of the natural world. The revelation of the unknown potential within the poem's space can only occur through the prior revelation of the known measure "Acre": both the unknown and the known emerge as co-equal potentialities within the poem's space, a space whose textuality suggests geography. The trees simultaneously "retard" and "further" the unknown —slowing the unknown to permit a revelation, and furthering it by engaging in the process of concealing.

Dickinson's poem exposes the complexity of our spatial experience, relying on a hermeneutical dialectic that springs from our preunderstandings (which filter and frame what appears to us within a particular space), feeds our understanding (as we receive data concerning various concrete, material entities that populate a space), and reinforces our postunderstandings (makes similar experiences of space more or less likely). We rarely, however, consider these variables as we navigate the multitude of kinds of spaces that frame our days: these could include the personalized space of a dwelling, the vectored space of a road, the dehumanizing space of a 
lobby, the efficient space of an office, the digital space of the internet, the fictional space of a narrative, the sacred space of a religious gathering, the social space of a pub. Each physical space interweaves wider cultural and historical narratives with an individual's own personal trajectory and extant structures of power-even those spaces that most desire to enforce static qualities (depositories of governmental, monetary, historical, commercial or religious power such as a courthouse, bank, museum, fast food franchise or mosque) cannot mandate how one experiences that space at that time.

This issue of the Iowa Journal of Cultural Studies invites readers to consider the spaces created by and cultivated within a variety of cultural products. Each essay offers a different informed, intentional awareness of space that readers can bring to spaces that they occupy, inhabit, preserve, and construct. Maintaining a similar stance toward space as that appropriated by Dickinson, these authors place readers into spaces that demonstrate how to navigate the variety of spaces that confront us, as they reflexively interpret communal and artistic spaces. These essays reveal the complex way that spaces become formulated; more specifically, these essays provide examples of reflexive contemplation concerning various reflections on how spaces are constructed. Moving from literature to visual images to video games, these essays occupy the space of Dickinson's poet, acknowledging the potential of spaces and the contributions of their various parts without forcing readers into spaces in certain ways. These reflections equip readers to critically engage with their environments in a way that parallels Dickinson's work-pushing us from our naïve engagements with our spaces into a more thoughtful appropriation and appreciation for what each space offers.

\section{The Truth of Experiences of Space}

To show how these essays provide academic cognates to Dickinson's poetic work, I will briefly discuss how we experience the truth of spaces, spaces more akin to the "Acre" than the perspectival space of potentiality that Dickinson provides. The primary level of experiencing space is pre-reflective, an unthinking collaboration that bridges one's preunderstood assumptions and the concrete materiality of the cultural or natural world. Two comportments inflect one's naïve attunement to a space. The first is receptive, allowing the surrounding environment to grasp, shape, and inform it: Dickinson's poem makes space for this attitude in its openness to the place given by the Acre and maintained in the confluence of the four trees. The second is projective, arising when one's values filter how the environment reveals itself: this occurs through the imposition of a desire to see deeds, plans or designs within the space. Both comportments depart from the poetic space intent on preserving possibilities and potentialities in order to enter into and engage with the surrounding environment. Receptive, we access the environment's potential for becoming a place. Thus attuned, we maintain the truth of the environment or space, appropriating it. Trees preserve or maintain the truth of a space by meeting the morning sun, testifying to the presence of wind, bearing witness to the sublime and beautiful patterns of weather that gradually help to shape the body of the 
tree. Although humans could attest to the truth of a place in this way, remaining physically rooted in one spot, we generally engage with places through language: like Dickinson, we allow the experience of the truth of a place to alter our words. We communicate this truth to others imagistically, rather than physically, weaving this truth into the space of a work of art.

Our projective experiences ignore the present, occupying the environment with a perspective rooted either in memories from the past or desires for the future. Generated by our preunderstandings, this comportment fixates on one potentiality maintained within a space or place without becoming aware of the possibility of other potentialities. Nostalgia therefore supplements an awareness of a favored street or park, infusing it with buildings whose functions changed long ago, permitting a spirit of joy or sorrow to haunt the place in spite of its present appearance. Optimism might look to a space and see it as altered, appropriated, made anew in a way that corresponds with one's values or desires: an Acre is seen as a potential wildlife preserve or as a potential grain field-and one can fear or rejoice at either potentiality based on one's prereflected value structure. These projective stances have in common a disregard for the present as it gives itself-in the case of the Acre, seeing it as a preserve or as a field pushes the experience away from the Acre's invitation to inhabit its way of existing as the space that it is.

One particularly insidious form of projection operates with an instrumental reason, driven by a calculative thought that challenges forth a certain profitable potentiality from the surrounding environments. This stance wholly ignores what is in order to embrace potential saleable wares that could spring forth. Enframed by a mindset that reduces the environment to its most functional alternatives, one completely ignores the unknown in a ravenous fixation on what can be itemized, secured, and produced. As Heidegger noted, such mindsets are dangerous because they are incredibly successful. We tend to reward those who are best able to eliminate what is unknown and mysterious, those who most precisely extract any number of functional, profitable goods from a space. Again, following Heidegger, the specific danger of this mindset is forgetting that a space had once held greater potentiality than that to which it had been reduced, ignoring that mysteries once clung to spaces, making them places worthy of reverence or awe.

In order to prevent assuming that receptivity is "good" while projection is "bad," it is important to reveal how these comportments function in spaces more frequently occupied by residents of the 21st century. We see "empty" places like those disclosed by Dickinson with increasing infrequency: more of our time is spent in any number of artificial environments. A receptive comportment in seemingly neutral places (classrooms, airport terminals, lobbies) reduces human potential to its most generic, interchangeable form. We learn to see ourselves as bodies that need to be processed and secured in a certain kind of way. We learn the type of music that one appreciates in such circumstances, the types of color schemes that one finds palatable, the type of magazine that one is certain to enjoy, the television programs that one would want to watch. Receptive, we become the one for whom such a space is made, we comport ourselves in ways appropriate to this space, or that space. As Henri Lefebvre has described, such spaces are abstracted-seemingly innocuous, 
they render everything interchangeable based on the lowest common denominators. In such spaces, engaging in works of creative projection introduces a space of defense against allowing that space to continue its work on us. Problematically, if we perform this work of projection unthinkingly, motivated even by a unreflected desire for the beautiful or peculiar, we end up living in an unreal world that we haunt as ghosts. We become unable to influence it directly.

The unique value of inhabiting a conceptual space that honors potentiality, such as Dickinson deployed, arises for precisely this reason—and validates her inclusion of potentially legal terms like "Acre" or "Deed." Dickinson draws attention to the importance of maintaining spaces as a multiplicity of potentialities (without object, direction or goal), open to furthering, or retarding, eventual aesthetic or commercial uses. This form of maintenance remains rooted in the way that each moment presents itself, pausing to acknowledge the truth of the moment as well as the more expansive truth of the space that appears through each moment's unique configuration. Maintaining moments and spaces in their fragile embrace of the unknown emerges as one truth of the space that the poet gleans from the Acre. A desire to embrace this unknown as such, instead of trying to reduce the mysterious to thoughts easily grasped by symbols, emerges as central to the project of maintenance. Remaining humbled by the unknown, it becomes more possible to attain a nuanced and controlled experience of space. On the one hand, maintaining the unknown requires that one keep watch over one's preunderstandings so as to allow the unknown to emerge in spite of them. On the other hand, maintaining the unknown can provide one a measure of defense against problematically reductive environments: one can become attuned with the occasions of the inexplicable that manifest within even the most controlled corporate environments. Instead of engaging with the world through a poetic or legal framework, Dickinson invites us to appropriate her space, one that she creates through an intentional reflexive engagement with her prereflective awareness. The essays in SPACE take up this challenge.

\section{III: SPACE}

Dickinson's mode of mindful maintenance-remaining aware of the many possibilities that frame and emerge within a given space-requires learning what types of frameworks shape spaces. What follows are essays that explore the boundaries of the spaces that we traverse on a daily basis, providing readers with an awareness of the importance of why creative appropriations of space are crucial from a variety of perspectives. Each essay in this issue of the Iowa Journal of Cultural Studies considers different factors that shape the worlds into which we are thrown. Each engages with a primary example that centers meditations on how power and language unjustly narrow possibilities otherwise open within a place.

First, Rachel Wagner's "This Is Not a Game: Violent Video Games, Sacred Space, and Making Ritual," explores how an understanding of ritual and religious practice makes sense of the unreal worlds manufactured in violent video games, 
and how such games alter the ways that those who immerse themselves in this dimension experience spaces in the world around them. More specifically, Wagner reveals the importance of understanding how spaces speak back to us in our receptive comportments, calling readers to be wary of participating in cultural spaces whose use of the sacred has been shorn of a notion of the holy. Filled with chilling descriptions of how secularized spaces promote mindless destruction, Wagner's essay forcefully highlights why it is crucial to engage with spaces as potentialities, not actualities.

The next two essays provide interpretations of textual spaces that disclose strategies for appropriating spaces in the reader's post-textual worlds. The second essay, "Reflected Spaces: 'Heterotopia' and the Creation of Space in William Gibson's Neuromancer" allows Wesley Dalton the opportunity to investigate the relationship between critical theory and literature by juxtaposing Gibson's descriptions of spaces within the seminal science fiction novel with Foucault's discussion of heterotopia and Jameson's work on total space. Dalton provides readers with an understanding of ways that "alternate" spaces reinforce (and generate) our conceptions of normal space, and more importantly exposes the role of narrating as an activity that creates the spaces in which we live. Third, "Into a Horizon I Will Not Recognize’: Female Identity and Transitional Space Aboard Nair’s Ladies Coupé,” probes how a novel recreates the technological space of a train in order to disclose how gender shapes - and reshapes - that space's particularities. Cassandra Bausman investigates why trains are unique spaces within the context of India, and shows how the novel allows readers-men and women-to investigate new possibilities for appropriating a space beyond how it might be given.

The final two essays portray different ways that language interweaves with the material, non-textual world. In the fourth essay, Jason Schneider explores the interdependent relationship between language and landscape, showing how spaces are framed by everyday speech and how our daily conversations arise from and are guided by the spaces we inhabit. His "From Urban Enclave to Ethnoburb: Discourse, Space, and Community in Polish Chicago” builds on his ethnographic work, revealing how Chicago neighborhoods occur as a nexus of social, political and economic experiences that blend the accidental and intentional. The final essay, "Richard Long's Passage as Line: Measuring Toward the Horizon,” looks at Long's work as embodied transformations of material spaces, powerful occurrences of dwelling poetically in the world. Interpreting Long's work through the ways that Martin Heidegger and Jean-Luc Nancy describe space and world, Antonia DapenaTretter focuses on how lines and circles have primary importance in our navigation of the spaces in our world. By showing how Long intentionally makes his mark on the world, Dapena-Tretter discloses how visual arts invite poetic dwelling, responsively reflecting and maintaining the truth of a space.

Although each essay individually demonstrates the advisability of embracing the space of potentiality, the set of essays as a whole reveals the importance of understanding how language, narrative and image are co-constitutive in producing our experiences of space. This collection reveals the importance of prioritizing a reflexive awareness of how we conceive of and enter into spaces, cautioning us about the 
importance of the senses, narrative and language as elements that are sufficient to the creation of space, but work most powerfully in concert. The importance of senses in detecting spaces is apparent, for sight, sound, smell and touch all provide information about the type of space that we have entered. Narrative and language seem to work almost invisibly behind the more sensorily accessible world, but act potently upon our preunderstandings of what a space is, or means. Stories show us how narrative capably creates a world that we can inhabit, and words (Acre, for instance), too, can singlehandedly produce a space. Language can be a powerful weapon for enacting beneficial changes and empowering marginalized figures; it should be used responsibly and intentionally. But although language is sufficient in creating space in a web of words, it is not necessary-images are equally self-sufficient in generating our awareness of what constitutes a space. In short, these essays corporately indicate how spaces are fragile, malleable and insidious. In a world increasingly devoted to spaces created to install a reduced vision of human potential, these essays provide a nuanced blueprint for how to access the perspective from which Dickinson writes by performing reconstructions of different spaces. Understanding the need for nuance, the hope in fragility, and the danger of certainty are crucial to creating new and challenging experiences of space in our own lives.

Ultimately, I hope that this collection introduces a heightened awareness of the multidimensional potentialities of spaces - and the comportments most conducive to authentic spatial experience. Acknowledging our own predispositions allows us to approach spaces - virtual, literary, "natural," architectural, industrial-as though each was its own unique creature, caged and eager to be recognized. Participating in the freeing of spaces requires a creative work of love that will transform ourselves and the world around us. Instead of mourning for spaces that no longer exist, or forcing spaces to shape themselves to conform to our most limiting expectations, we need to rejoice in the availability of spaces and the unique gift each offers to us, now. The mediation of these essays promotes a sense of inhabitation that will awaken our capacity to join in a transformation of self and world in an enriching and inspiring absorption.

\section{Dan Boscaljon}

Daniel Boscaljon earned a PhD in Religious Studies (2009) focused on modern religious thought and a PhD in English (2013) focused on nineteenth-century American literature. He is the author of Vigilant Faith: Passionate Agnosticism in a Secular World (University of Virginia Press, 2012) and the editor of two volumes: Resisting the Place of Belonging (Ashgate, 2012) and Hope and the Longing for Utopia (Wipf and Stock, 2014). He is currently editing a book on teaching religion and literature and constructing a project that explores secularism in nineteenthcentury America.

\section{Works Cited}

Bachelard, Gaston, and M Jolas. The Poetics of Space. Boston: Beacon Press, 1994. Print. 
Benfey, Christopher. Emily Dickinson and the Problem of Others. Amherst, MA: The U of Massachusetts P, 1984. Print.

Casey, Edward S. The Fate of Place. University of California Press, 2013. Print.

Clingerman, Forrest. Interpreting Nature: The Emerging Field of Environmental Hermeneutics, 2014. Print.

Dickinson, Emily, and R W. Franklin. The Poems of Emily Dickinson: Reading Edition. Cambridge, Mass: Belknap, 2005. Print.

Gerhardt, Christine. “'often Seen - but Seldom Felt’: Emily Dickinson's Reluctant Ecology of Place.” Emily Dickinson Journal 15.1 (2006): 56-78. Print.

Harvey, David. The Condition of Postmodernity: An Enquiry into the Origins of Cultural Change. Oxford, UK: Blackwell, 1990. Print.

Heidegger, Martin. Poetry, Language, Thought. New York: Harper \& Row, 1971. Print.

Hughes, Thomas P. Human-built World: How to Think About Technology and Culture. Chicago: University of Chicago Press, 2004. Print.

Lane, Belden C. Landscapes of the Sacred: Geography and Narrative in American Spirituality. Baltimore, Md: Johns Hopkins University Press, 2002. Print.

Lefebvre, Henri. The Production of Space. Oxford, UK: Blackwell, 1991. Print.

Miller, Cristanne. Emily Dickinson, a Poet's Grammar. Cambridge, MA: Harvard University Press, 1987. Print.

Scharlemann, Robert P. The Being of God: Theology and the Experience of Truth. New York: Seabury Press, 1981. Print.

Tuan, Yi-fu. Space and Place: The Perspective of Experience. Minneapolis: University of Minnesota Press, 1977. Print.

Webster, Noah. An American Dictionary of the English Language: Exhibiting the Origin, Orthography, Pronunciation, and Definition of Words. New York: Harper, 1844. Web. 